ISSN 1991- 8690

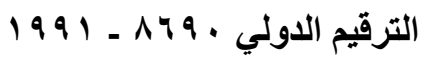

website : http:// jsci.utq.edu.iq

Email: utjsci@utq.edu.iq

\title{
Characterization of silences acid dosimeter for gamma-radiation dosimetry
}

\author{
Riyadh. CH.Abul -Hail \\ H.F Hussein \\ H.Bakr* \\ "University of Basrah - College of Education -Department of physics-Basrah
}

\section{$\underline{\text { Abstract }}$}

Silences acid has been investigated as a dosimeter for high doses of Gamma radiation through measuring the induced changes in optical absorbance from (315-900) $\mathrm{nm}$ at room temperature. It was found that the absorbance increased with increasing absorbed Gamma-dose. Also, the dose rate and post irradiation fading of optical absorption spectra has been studied. The results of this preliminary study show that Silences acid may be applied as a simple optical absorbance detector for dose measurement in the dose range (5 - 28$) \mathrm{kGy}$.

Keywords : Gamma-ray, dose-response, dose rate, optical absorption, fading .
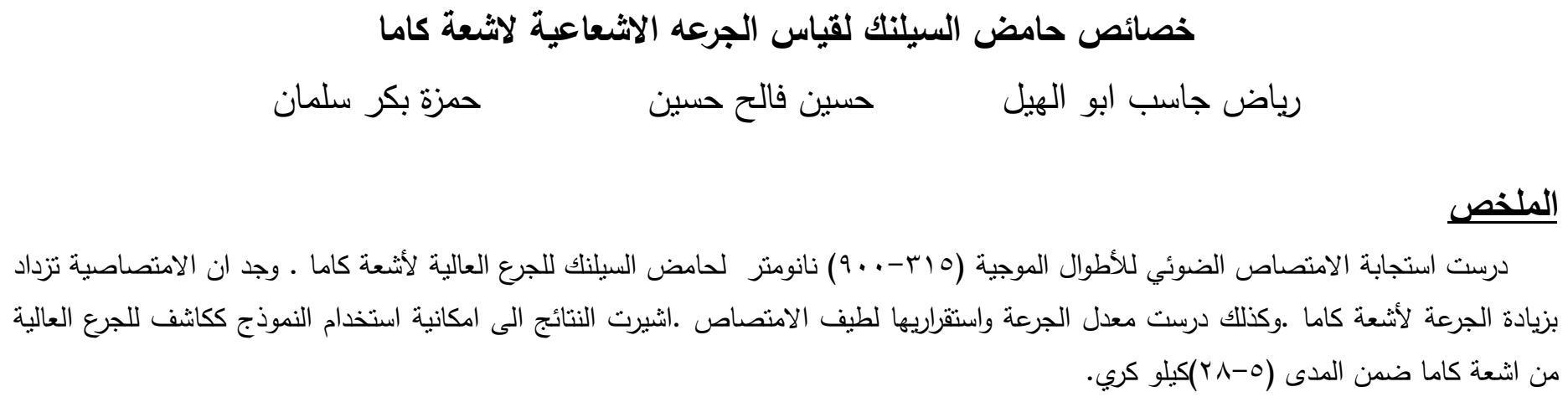

\section{1-Introduction}

The use of the change of optical absorption, of some plastics and glass materials with the given radiation dose is considered one of the methods that has greatly interested many researchers in the field of radiation dose measurement. This method has been known for hundred of years .they noticed that the colors of some materials were changed when its exposure to radiation dose, which attributed to the radiation damage. Radiation-induced changes in the optical density of glasses and plastics have been used occasionally to measure radiation quantity. Changes in the optical density are determined by measuring the transmission of visible or ultraviolet light through the materials before and after exposure to radiation. In fact, there are many materials that show changes in optical absorption when exposed to high absorption doses. Since gamma-rays penetrating power and ability to travel great distances is much higher, it finds wide range of applications including industrial process monitoring, medical imaging, environmental safety, remediation, national security, treaty verification and basic science [1-3]. Therefore it necessitated the people engaged in radiation dosimetry to wear the dosimeter device to ensure that they do not receive more than recommended dose level. The requirement of radiation dosimeter or sensor includes high sensitivity and linear performance over the intended energy range; real-time response, low noise, and acceptable reliability under the exposure conditions[4] In this work thin films of Silences acid were investigated to be applied as dosimeteric material evaluating the radiation dose response to $\mathrm{Cs}-137$ gamma radiation. 


\section{2-Experimental}

The thin films of the Silences acid were prepared by using cast method .Silences acid powders ,obtained from Merck company .Dissolved in dimethylformaide (D MF).The concentration of silences acid molecules in a solvent $(10 \mathrm{mg} / \mathrm{ml})$, the mixture was stirred at room temperature for 2 hours to yield a homogeneous solution. The solution deposited on a glass substrate by casting method at room temperature.Silences acid thin film were irradiated with Cs-137 gamma source with the activity of the source an exposure rate $0.56 \mathrm{~Gy} / \mathrm{min}$ .The optical absorption spectra were recorded using a spectrophotometer mark (CE-7200). It is supplied from (CECIL),England .Which is measure for the interval wavelengths from (190-900)nm.During gamma-ray irradiation $3 \mathrm{~mm}$ thick Plexiglas s was used with each sample in order to attain electronic equilibrium[5].

\section{3-Results and Discussion \\ 3-1.Optical properties}

The optical properties of material are important, as they provide information on the electric band structures, localized states and types of optical transitions. Typical optical absorption spectra plots against wavelength of Silences acid samples of irradiated solid salt in the dose range (5-28)kGy are shown in Fig(1). From this it is evident that the optical absorption spectral distribution is sensitive to the radiation influence at the wavelength $303(\mathrm{~nm})$.Table 1 shows the results of band separation of the induced absorption spectra at $0,5,10$, 18 and $28 \mathrm{kGy}$. It was found that gamma radiation dose has no influence on the absorbance band position .The band peak position were relatively constant and only the heights and the area of the band changed. These result suggest that the increasing of gamma radiation dose affects only. In Fig (2) shows the increase in the normalized absorbance with the increase in radiation dose. It is clear from this figure that the dose response curve is linear in the range from (5-28) $\mathrm{kGy}$.The linear of the dose-response curve can be used as a good means for gamma dosimetry in the stated range. The variation of optical absorbance with doses can be explained as the change in the degree of disorder. From the density of state model, it is known that optical energy gap decreases with an increasing degree of disoeder of amorphous phase[6] the influence of radiation depends on both the dose and the parameter of the films including their thickness, the degradation is more severe for the higher dose and the thinner films[7].
Table 1.Results of band separation for the induced absorbance spectra.

\begin{tabular}{|cccc||}
\hline Dose(kGy) & $2(\mathrm{~nm})$ & FWHM(nm) & A(arb.units) \\
0 & 303 & 34 & 33.75 \\
5 & 303 & 36 & 48.75 \\
10 & 303 & 37 & 55 \\
18 & 303 & 38 & 72.50 \\
28 & 303 & 40 & 92.50 \\
\hline
\end{tabular}

\section{3-2.Dose rate effect}

In order to investigate the effect of exposure dose rate on the optical absorption of Silences acid samples set of sample has been irradiated to $5 \mathrm{kGy}$ at two different sources one of them $12 \mathrm{mrad} /$ minute and the other source $56 \mathrm{rad} /$ minute we see that effect of dose rate on the response of the Silences acid thin film is very small, see Table(2)

Table (2)Effect of dose rate on the absorbance of solution salt sample irradiated to $5 \mathrm{kGy}$

\begin{tabular}{|cc|}
\hline DOSE RATE & ABSORPANCE (arb.units) \\
$12 \mathrm{mrade} /$ minute & 0.615 \\
$56 \mathrm{rad} /$ minute & 0.620 \\
\hline
\end{tabular}

\section{3-3.Fading}

All material that show a low fading in the stored glow at room temperature are characterized by their good stability. As for those with high fading, they are unstable that is why attention should be paid to these characteristics when material are used to measure radiation doses. In Fig(3).the post irradiation fading of optical absorption spectra at room temperature is shown. Approximately a 40 days is required to the absorbance spectra at $303 \mathrm{~nm}$ to reduce to half of its value just after the gamma irradiation. This fading dose not affect seriously the potentiality of this polymer as gamma dosimeter particularly for short irradiation intervals and high dose rates[ 8].

\section{$\underline{\text { 4-Conclusion }}$}

From the Study of the ability to use Silences acid as a dosimeter, we came out with the following conclusions:

1. The appearance of one clear peaks in the absorbance spectra at $303 \mathrm{~nm}$. 
2. The band peak position at $303 \mathrm{~nm}$ were relatively constant and only the heights and the area of the band changed and the fading dose not affect seriously the potentiality.

3. preliminary in visitation of the optical absorption properties of Silences acid suggest it may a useful accidental dosimeter for high dose. .

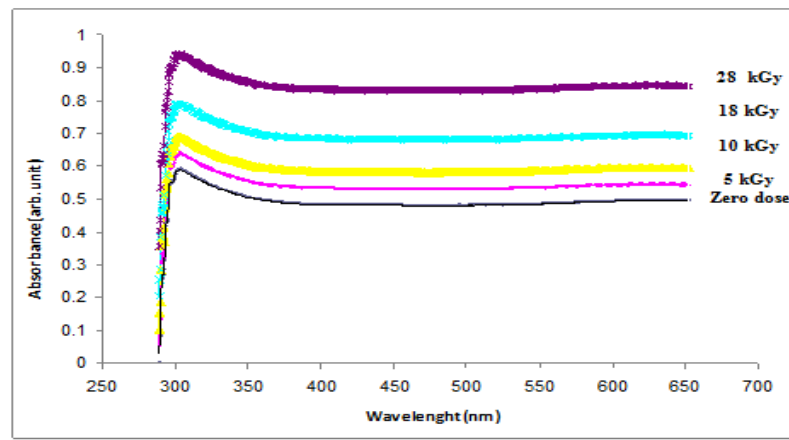

Fig 1. Absorption spectra of $\mathrm{H}_{2} \mathrm{Seo}_{3}$ for different doses.

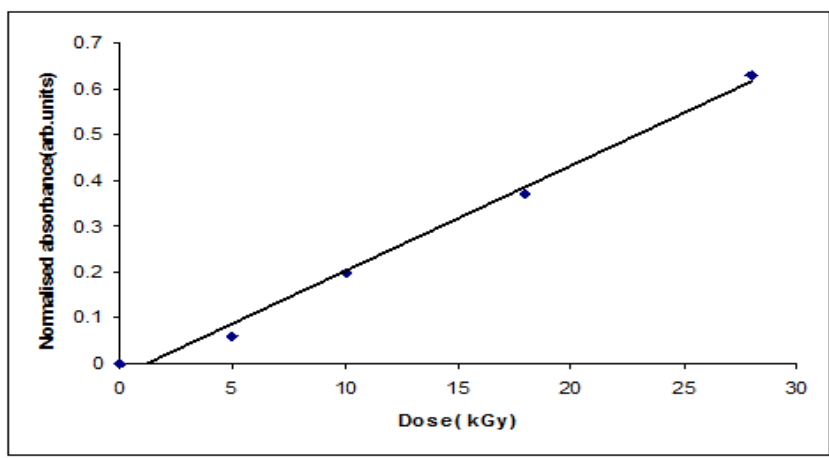

Fig 2.Varition of absorbance with Gamma-dose at (303) nm.

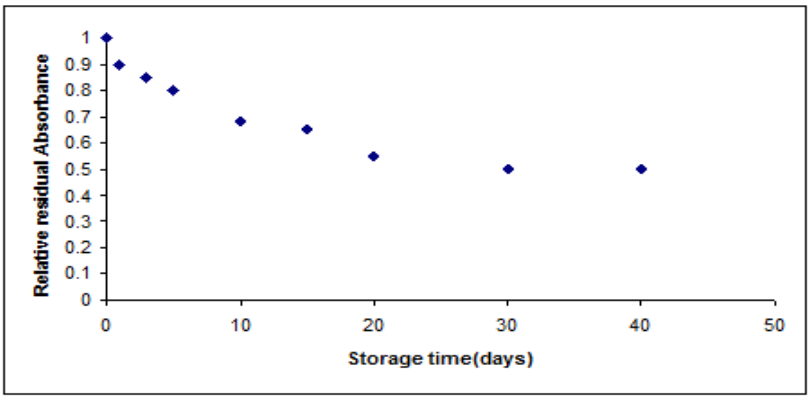

Fig.3 Effect of storage time after irradiation on the absorbance Gamma-irradiated $\mathrm{H}_{2} \mathrm{SeO}_{3}$.

\section{$\underline{\text { 5-References }}$}

1- Arshak.K, . Korostynska.O, Thin film pn-junctions based on oxide materials as gamma-radiation sensors, Sens. Actuators A 113 (2004) 307-311.

2- Arshak .K, . Korostynska.O, Gamma radiationinduced changes in the electrical and optical properties of tellurium dioxide thin films, IEEE Sens. J. 3 (6) (2003) 717-721.

3- Ibrahim .A.M, . Soliman .LI, Effect of _-irradiation on optical and electrical properties of Se1-xTex, Radiat. Phys. Chem. 53 (1998) 469-475.

4- S. Audet.S. Steigerweld.J, in: S.M. Sze (Ed.), Semiconductor Sensors, Wiley, New York, 1994, p. 271.

5-J.R.Cameron, N.Suntharalingan and G.kenney; Thermoluminescent Dosimetry University of Wisconsin press 1968.

6-Kurik, M.V . Urbach rule . Physica Status Solid A 1971,8,9-45.

7-Tanassova, E.; Paskalea, A.; Konakova, R.; Spassov,D.;Mitin,V.F.Infuuence of gammaradiation on thin $\mathrm{Ta}_{2} \mathrm{O}_{5}-\mathrm{Si}$ structures .Microelectronics Journal $2001,32,553-562$.

8-Khazal K.A.R and Habubi N.F .Isotopenpraxis 1990 265 pp237-238. 